
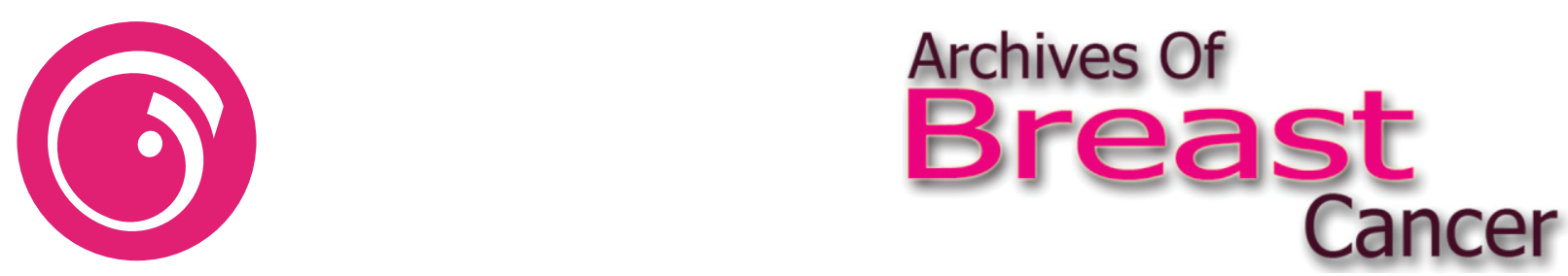

DOI: $10.32768 / a b c .2021818-13$

By the Metrics Surgical Oophorectomy Plus Tamoxifen is the First Adjuvant Treatment Option for Premenopausal Women with Hormone Receptor Positive Breast Cancer

\author{
Richard R. Love ${ }^{\star a}$ \\ ${ }^{a}$ Department of Computer Science, Marquette University, Milwaukee, WI, USA
}

"The right measure for successful health care isn't about the maximum possible for a few, but the average for everyone... and the minimum opportunities available to even those with the fewest resources and privileges"

"How you define the problem determines whether you solve it.",

Outcomes for the majority of women with breast cancer, most of whom, but hardly all, do not live in high-income countries, are poor. ${ }^{3}$ The breast cancer sub-group of premenopausal women with hormone positive tumors is large: at a minimum: 550,000 total new cases/year, 420,000 of whom come from lowand middle-income countries (LMICs), with $82 \%$ of the global population. Based on Globocan estimates for all new breast cancer cases for 2018 at 2.088 million, this subgroup number may be as high as 700,000 cases. $^{3}$

For this specific population, the impact of optimal treatment is large. The Early Breast Cancer Trialists' Group found a risk reduction of $25 \%$ in death at 10 years with 5 years of tamoxifen treatment. ${ }^{4,5}$ The additional benefits of ovarian suppression or ablation added to tamoxifen suggest risk reductions for death of as much as $42 \%{ }^{6-8}$ These data suggest that in a premenopausal population of half axillary node-positive patients with a 10-year overall survival of $55-60 \%$ without any adjuvant treatment, with optimal 5-year adjuvant endocrine therapy this figure might increase to $75-78 \%$. These estimates, therefore, suggest that $80-100,000$ of the 420,000 (minimally) low-and middle-income country women diagnosed annually, at greater absolute risk for death without optimal treatment,

\footnotetext{
* Address for correspondence:

Richard R. Love, M.D.

Address: 2708 Columbia Road, Madison, WI 53705, USA.

Tel: +16086987881

Fax: +1 608238788

Email: richardibcrf@gmail.com
}

who could be saved for 10 years, instead die.

What is the problem? Among many issues, the following stand out:

- Human rights challenges. In many countries, women do not have permission to seek medical care for themselves. If it were widely known that attainable, affordable, and effective treatment was available, this might mitigate some of these restrictions. ${ }^{9}$

- Barriers to seeking care. Women do not seek interventions for breast problems they know they have. Many women in LMICs don't seek care because they know that in their medical systems, financial resources will be demanded for diagnosis and treatment, money their families do not have.' 9

- Financial and health system operational issues. Increasingly, health care systems globally operate on business models, with high levels of corruption in many LMICs. For most patients, their systems are byzantine, and timeconsuming. ${ }^{9}$

In these broad contexts, for premenopausal women with hormone receptor-positive breast cancer:

- Following from leading cancer organization guidelines, SO (surgical oophorectomy) plus tamoxifen as a treatment choice is not offered. ${ }^{11}$

- Because of financial barriers and treatment nonadherence, many patients, particularly those in LMICs (the majority), if they have operable disease and do undergo primary surgery, appear not to get any or enough adjuvant treatment to provide maximally achievable outcome benefits: prevention of disease recurrence and death. ${ }^{12}$

- Together with assumptions that SO or ovarian ablation and ovarian function suppression are equivalent clinical treatments, SO and $\mathrm{GnRH}$ treatments are inappropriately considered as biologically and therapeutically equivalent. ${ }^{11}$ 
- When offered, there is incomplete consideration of the SO + T option by patients because of no mention by physicians of data regarding multiple key metrics of value and quality of this intervention. ${ }^{11}$

- Incomplete/immature data on SOFT/TEXT investigated/recommended treatments regarding key metrics, particularly long-term secondary effects. $^{8}$

- Unrealistic considerations and discussions of host differences about symptoms.

- Much lower clinical practice compliance with treatment programs than in research studies, and limited approaches to treatment in-adherence problems. ${ }^{12}$

- A dominant tumor-biology-focused treatment paradigm exists when there are strong suggestions that a host biology-focused treatment paradigm is also likely. ${ }^{13}$

- Individual patient (in researchers' experiences) versus global public health treatment paradigms, with limited consideration of the equity issues associated with these paradigms. ${ }^{14}$

The breadth of these problems as causal explanations emphasize the importance of patientcentric issues in clinical care. In many ways, they are all of a whole. This lengthy introduction has been offered to frame appropriately, constructively, broadly, comprehensively, and for women globally, the rationale and substance of this communication.

Consider then with the six Institute of Medicine (IOM) quality of health care metrics, relevant $\mathrm{SO}+\mathrm{T}$ data from the author's two phase III randomized clinical trials (and peripherally one additional trial in metastatic disease in consideration of one issue -host paradigms), an ECOG trial, and the updated SOFT/TEXT trial report. ${ }^{4,5,14-18}$ Additionally, note data from other earlier adjuvant trials where SO has been a treatment: the very first adjuvant trials considered in meta-analysis, and Scottish, Danish, and French trials. ${ }^{4,5,19-21}$

The six IOM quality of care metrics are efficacy, safety, efficiency, patient-centeredness, timeliness, and equity. ${ }^{22}$ Addressing the data about these measures with respect to $\mathrm{SO}+\mathrm{T}$ in order:

\section{A. Efficacy/Effectiveness}

A data-supported place for SO in the adjuvant therapy of breast cancer was created by the EBCCTG meta-analysis which included 4 trials, first individually reported on beginning in $19700^{4,5}$ The individual patient data from these trials and those involving radiation to the ovaries, with what would be considered significantly less-thanrigorous methodologies today, and in the absence of patient tumoral hormone receptor data, looked at together, suggested that ovarian function ablation or suppression with radiation, conferred long-term recurrence free (DFS) and overall survival (OS) benefits. $^{4,5}$

A Scottish trial in women with axillary node positive breast cancer, found ovarian ablation provided equivalent outcome benefits to those from CMF chemotherapy. ${ }^{21}$ In the sub-set of patients whose tumors were later assessed for hormonal receptors, those patients with hormone receptor positive tumors benefitted more from ovarian ablation. A Danish trial in hormone receptor positive patients found ovarian ablation and CMF to be equivalent therapies in efficacy. ${ }^{19}$

A trial in premenopausal women in Vietnam and China with operable breast cancer, $52 \%$ of whom were axillary node positive, unselected for hormone receptor status at the time of primary treatment, found that in the patients subsequently determined to be estrogen receptor positive, there were 7 year disease-free and overall survival risk reductions of 0.46 and 0.54 , respectively. ${ }^{6,17}$

A French trial in axillary node-positive, tumor hormone receptor- positive patients found ovarian ablation plus tamoxifen to be superior to FAC chemotherapy. ${ }^{20}$

An underpowered American Intergroup study in axillary node negative, hormone receptor positive patients found SO plus tamoxifen to give better overall survival at 5 years than tamoxifen alone with a risk reduction of 0.5 (OS $97.6 \%$ versus $95.2 \%$ ) (N.S.). ${ }^{16}$

A trial in hormone receptor positive Vietnamese and Filippine women found, in explanatory analyses, that patients with true follicular or luteal menstrual phase status confirmed by blood progesterone testing, had significantly better DFS and OS compared to patients with unconfirmed luteal (or prolonged follicular or anovulatory) status (history of luteal phase, but low progesterone levels). ${ }^{15}$ This same observation was made in a SO plus tamoxifen study in women with hormone receptor positive metastatic breast cancer. ${ }^{18}$

In the recently updated SOFT/TEXT trials analyses of ovarian suppression by GnRH agonist treatment plus tamoxifen or GnRH treatment followed by SO plus tamoxifen, versus tamoxifen alone, 8 -year OS risk reductions of 0.33 without, and 0.41 with chemotherapy (higher risk patients), were observed with the combined ovarian plus tamoxifen treatments, for both $\mathrm{p}=0.01$. $^{8}$

In two trial data sets, the combination of $\mathrm{SO}$ or GnRH plus tamoxifen has been suggested to be more beneficial in Her-2neu positive patients ${ }^{8,23}$

It is self-evident, but important to note that assigned $\mathrm{SO}$ in all of the above trials was received by practically all of the studied patients, while in the SOFT/TEXT trials early discontinuation of the GNRH plus tamoxifen treatment occurred in 19.3\% of participating subjects in contexts where treatment for 5 years was being studied. ${ }^{8}$ Based on data about nonadherence to tamoxifen alone treatment (see 
below), in non-research settings early discontinuation rates might be expected to be even higher. ${ }^{12}$ This is but one of several differences between patients treated with GnRH therapies versus SO. In the SOFT/TEXT trials' interventions, GnRH was given as noted for variable periods less than the planned 5 years. There is no ability to monitor for GnRH efficacy in individual patients, so there is no certainty from month to month of biological effect. GnRH followed by $\mathrm{SO}$ beyond 6 months was a treatment option in SOFT/TEXT trials, but SO was done variable times over the 5 years with unspecified treatment gaps between treatments and with uncertain hormonal signaling effects. The duration of follow up in the SOFT/TEXT trials provided limited long-term allcause mortality information. ${ }^{8}$

While the SOFT/TEXT trials investigated the issue of ovarian suppression plus aromatase inhibitor treatment, at 8 years there was no significant difference in overall survival compared with ovarian suppression plus tamoxifen treatment, this at a timepoint 3 years after completion of the adjuvant therapies. ${ }^{8}$

Finally, regarding efficacy of SO plus tamoxifen in the contexts described above, population data on tamoxifen nonadherence strongly suggest that in clinical practice tamoxifen consumption falls dramatically over the 5 years currently prescribed period, and that perhaps but $1 / 3^{\text {rd }}$ of women, even in high-income countries, take the medication for this period. ${ }^{12}$ Further, regarding absolute overall benefits of adjuvant hormonal therapies, these have to be understood in the contexts now of additional benefits to these patients from adjuvant radiation therapy, and long term (between year 5 and 10) hormonal therapies, particularly tamoxifen. ${ }^{24-26}$

\section{Conclusions regarding efficacy of $\mathrm{SO}+T$}

The above reviewed specific SO studies demonstrate a consistent overall, and withinseveral-studies-consistent picture of efficacy from $\mathrm{SO}$ plus $\mathrm{T}$ greater than that from $\mathrm{SO}$ alone or tamoxifen alone, and equivalent or perhaps with some twists (timing of surgery, for example; or better treatment adherence), efficacy to standard widely available chemotherapy regimens. These superior benefits are seen in node positive as well as node negative patients. Over the first 10 years following diagnosis and treatment, SO plus tamoxifen is clearly and significantly an optimally effective treatment, in major part, at the population level, because when chosen, surgical oophorectomy is always received.

\section{B. Safety and toxicity side effects}

In high-income country studies, with often limited follow-up periods of 5-10 years, immediate symptomatic side effects are well-reported, but longterm clinical outcomes are less documented. For the symptoms data, what is important to note is that particularly the vasomotor symptoms vary in frequency, intensity, and duration among populations. In Asian populations, the intensity and duration of vasomotor symptoms following SO plus tamoxifen were indistinguishable from these metrics in untreated women after one year. ${ }^{27}$ In contrast, in American and European populations, these symptoms were more significant. ${ }^{8,16}$

For bone mineral density, SO plus tamoxifen causes bone loss at only the lumbar spine site, for one year, and is associated with no significant loss at the hip at all. ${ }^{28}$ This is a significant salutary benefit, suggesting that such treatment does not need to be supplemented with bisphosphonate therapies with their own financial costs and toxicities. This is not the case with GnRH plus tamoxifen or aromatase treatments. ${ }^{28}$

Because of the use of tamoxifen in postmenopausal women with breast cancer and as a chemoprevention drug, there are considerable data to allow estimates of the long-term secondary effects of SO plus tamoxifen, summarized in Table 1.

As can be read here, these data are remarkably reassuring that this treatment has long-term overall benefits which far exceed those often overemphasized for endometrial cancer and thromboembolism. What

Table 1. Estimated long-term secondary effects of SO+T*

\begin{tabular}{|c|c|}
\hline All-cause mortality & Decreased $^{29}$ \\
\hline CHD mortality** & Decreased $^{29,30}$ \\
\hline Myocardial infarction & Decreased $^{29,31}$ (in 2/5 studies) \\
\hline Stroke & Decreased $^{31}$ (in 3/6 studies) \\
\hline VTE/PE*** & Limited in women under age $501^{5,17,32}$ \\
\hline Lung cancer & Decreased $^{29}$ \\
\hline Colon cancer & No impact ${ }^{33}$ \\
\hline Endometrial cancer & Excess affecting $0.2 \%$ / year with very rare deaths ${ }^{15,17,34,35}$ \\
\hline$\underline{\text { Ovarian cancer }}$ & Decreased \\
\hline
\end{tabular}


is also clear is that at present such long-term data are not available for GnRH plus tamoxifen or aromatase inhibitor treatments, and also that there are multiple reasons to expect that when available data on the outcomes listed in Table 1, will offer a much less favorable picture for $\mathrm{GnRH}$ treatments than those for SO plus tamoxifen.

Other than vasomotor symptoms, other specific side effects of SO should be noted. Among 1101 patients who received SO in two adjuvant studies primarily in Vietnam, China, and the Philippines, there was no 30-day mortality, and 4 patients only developed pneumonia (2) or deep vein thromboses (2). ${ }^{15,17}$ Most of these SO procedures were done under the anesthesia done also for the primary breast surgery. All of these patients were fully informed of the irreversible nature of this procedure on their menopausal status and ability to conceive, and provided written informed consent. ${ }^{15,17}$ In one major clinical trial site in Manila, 3 patients of $336(<1 \%)$, refused SO plus tamoxifen treatment, possibly because of irreversible and inability-to-conceive treatment consequences.

In summary, with respect to the IOM safety metric, SO plus tamoxifen is comprehensively described over short and long terms and the overall impact on women's health is very favorable.

\section{Cost efficacy/efficiency/net benefit for cost}

For patients, SO plus tamoxifen is much more cost-effective or gives more net health benefit for much lower patient payment, than GnRH plus tamoxifen. SO plus tamoxifen treatment maximizes the impact of available medical resources, when both indirect and direct costs for both providers and patients are considered. Perhaps more so in low- and middle-income than in high-income countries, financial issues come to the fore in treatment decisions. A breast self-examination trial in the Philippines was abandoned because patients who had breast tumors did not seek care because they assessed that they did not have the financial resources to have treatment. ${ }^{36}$ In the United States, the American Society of Clinical Oncology considers delivering value to be a major driver of change in health care delivery, and has expressed concerns regarding the financial toxicity of expensive cancer therapies. ${ }^{37}$ The cost -efficacy of SO plus tamoxifen treatment has been estimated at $\$ 351$ per year of life saved, a level of return comparable to those suggested for very effective vaccinations. ${ }^{17}$

SO plus tamoxifen requires inpatient surgery accomplishable in most settings globally together with the primary breast surgery, with financial costs covered. Tamoxifen, in most settings, requires out of pocket costs for patients, but of manageable levels. No additional therapies are required in particular because of an absence of bone loss toxicity. In contrast, GnRH therapies require monthly (recommended) or 3 monthly physician visits with associated significant direct and indirect patient costs, and as noted above, 5 years of treatment are the standard of care.

\section{Patient-centeredness}

This important metric addresses tailoring treatment to patient needs, values, and preferences. SO treatment absolutely requires open discussion with patients about this option in detail, and as such, if chosen by patients, meets the metric requirements. In contrast, full exposition of GnRH treatment with all its components, clearly is not well patientcentered, and is significantly impractical.

\section{E. Timeliness}

$\mathrm{SO}$, treatment is a one-time intervention done together with primary surgery. Once completed, patients must incur the benefits. There are no delays in treatment associated with unavailability of medicines and finances, or schedules of patients and caregivers, as occur regularly with $\mathrm{GnRH}$ treatments. This "one stop" metric of SO makes it a better treatment than $\mathrm{GnRH}$.

\section{F. Equity}

Essentially all women globally can get SO treatment, which meets the need offered by Tufeki for successful health care. ${ }^{1}$ SO treatment limits corruption factors which play out over time with GnRH treatments. SO plus, tamoxifen treatment provides consistent quality of care to all patients and is a socially just treatment. With GnRH treatments, major financial issues and dysfunctional health systems interfere with delivering this treatment to populations for their maximal benefit. Table 2 summarizes the fore-presented data on IOM metrics.

Table 2. Summary: Adjuvant SO+T by the 6 IOM metrics

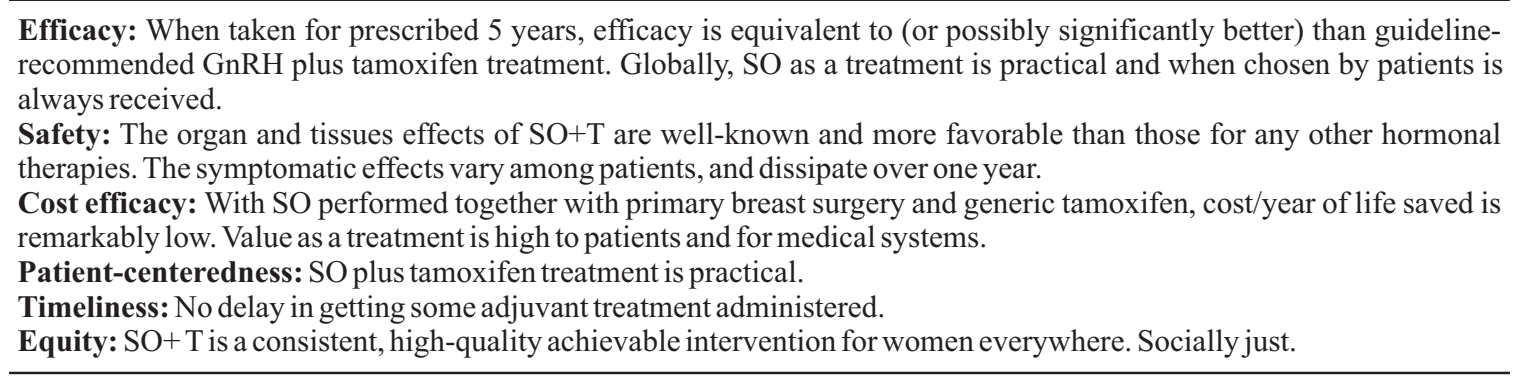


Globally, all 550,000-700,000 women annually ( $1 / 3$ rd of all new cases) for whom adjuvant hormonal therapies are strongly indicated, should be provided information on the 6 metrics of quality of care for adjuvant treatments, and given the option of SO plus tamoxifen treatment. Treatment standards are local not global; thus, particular circumstances, both patient and medical system may determine whether $\mathrm{SO}+\mathrm{T}$ is a reasonable option. ${ }^{38}$

\section{Conflict of Interest}

The author reports no conflicts of interest.

\section{Funding sources}

None.

\section{References}

1. Tufekci Z. Data-driven medicine will help people: But can it do so equally. The New York Times Magazine. 2018.

2. Markman A. How you define the problem determines whether you solve it. Harvard Business Review. 2017:16-8.

3. Bray F, Ferlay J, Soerjomataram I, Siegel RL, Torre LA, et al. Global cancer statistics 2018: GLOBOCAN estimates of incidence and mortality worldwide for 36 cancers in 185 countries. CA: A Cancer Journal for Clinicians. 2018;68(6):394-424.

4. Clarke M, Collins R, Darby S, Davies C, Elphinstone P, et al. Early Breast Cancer Trialists Collaborative Group (EBCTCG). Effects of radiotherapy and of differences in the extent of surgery for early breast cancer on local recurrence and 15-year survival: an overview of the randomised trials. Lancet. 2005;366(9503): 2087-106.

5. Howell A, Ribeiro G, Swindell R. Systemic treatment of early breast cancer by hormonal, cytotoxic, or immune therapy. 133 randomised trials involving 31,000 recurrences and 24,000 deaths among 75,000 women. Early Breast Cancer Trialists' Collaborative Group. 1992.

6. Love RR, Van Dinh N, Quy TT, Linh ND, Tung ND, et al. Survival after adjuvant oophorectomy and tamoxifen in operable breast cancer in premenopausal women. Journal of Clinical Oncology. 2008;26(2):253-7.

7. Pan H, Gray R, Braybrooke J, Davies C, Taylor $\mathrm{C}$, et al. 20-year risks of breast-cancer recurrence after stopping endocrine therapy at 5 years. New England Journal of Medicine. 2017;377(19): 1836-46.

8. Francis PA, Pagani O, Fleming GF, Walley BA, Colleoni $\mathrm{M}$, et al. Tailoring adjuvant endocrine therapy for premenopausal breast cancer. New England Journal of Medicine. 2018;379(2):122-37.

9. Story H, Love R, Salim R, Roberto A, Krieger J, et al. Improving outcomes from breast cancer in a low-income country: lessons from Bangladesh. International journal of breast cancer. 2012;2012.

10. Fathalla MF. Human rights aspects of safe motherhood. Best Practice \& Research Clinical Obstetrics \& Gynaecology. 2006;20(3):409-19.

11. Burstein HJ, Griggs JJ, Prestrud AA, Temin S. American society of clinical oncology clinical practice guideline update on adjuvant endocrine therapy for women with hormone receptorpositive breast cancer. Journal of Oncology Practice. 2010;6(5):243-6.

12. van Herk-Sukel, M.P., van de Poll Franse, L.V., Voogd, C.A., et al.: Half of breast cancer patients discontinue tamoxifen and any endocrine treatment before the end of the recommended treatment period of 5 years: a population-based analysis. Breast Cancer Research and Treatment. 2010; 122: 843-51.

13. Love RR, Love SM. Peri-operative biology in primary breast cancer: a credible therapeutic target. Breast cancer research and treatment. 2016;156(3):411-3.

14. Love R, Ginsburg O, Coleman C. Public health oncology: a framework for progress in low-and middle-income countries. Annals of Oncology. 2012;23(12):3040-5.

15. Love RR, Laudico AV, Van Dinh N, Allred DC, Uy GB, et al. Timing of adjuvant surgical oophorectomy in the menstrual cycle and diseasefree and overall survival in premenopausal women with operable breast cancer. JNCI: Journal of the National Cancer Institute. 2015; 107(6).

16. Tevaarwerk AJ, Wang M, Zhao F, Fetting JH, Cella D, et al. Phase III comparison of tamoxifen versus tamoxifen plus ovarian function suppression in premenopausal women with node-negative, hormone receptor-positive breast cancer (E-3193, INT-0142): a trial of the Eastern Cooperative Oncology Group. Journal of Clinical Oncology. 2014;32(35):3948.

17. Love RR, Duc NB, Allred DC, Binh NC, Dinh NV, et al. Oophorectomy and tamoxifen adjuvant therapy in premenopausal Vietnamese and Chinese women with operable breast cancer. Journal of Clinical Oncology. 2002;20(10):2559-66.

18. Love RR, Hossain SM, Hussain MM, Mostafa MG, Laudico AV, et al. Luteal versus follicular phase surgical oophorectomy plus tamoxifen in premenopausal women with metastatic hormone receptor-positive breast cancer. European Journal of Cancer. 2016;60:107-16.

19. Ejlertsen B, Mouridsen HT, Jensen M-B, Bengtsson $\mathrm{N}-\mathrm{O}$, Bergh J, et al. Similar Efficacy for Ovarian Ablation Compared With Cyclophosphamide, Methotrexate, and Fluorouracil: From a Randomized Comparison of Premenopausal Patients With Node-Positive, Hormone Receptor-Positive Breast Cancer. Journal of 
clinical oncology. 2006;24(31):4956-62

20. Roche H, Mihura J, De Lafontan B, RemeSaumon M, Martel P, et al. Castration and tamoxifen versus chemotherapy (FAC) for premenopausal, node and receptors positive breast cancer patients: A randomized trial with a 7 years median follow up. European Journal of Cancer. 1996;32(S2):35.

21. Scottish Cancer Trials Breast Group and ICRF Breast Unit Guy's Hospital, London. Adjuvant ovarian ablation versus CMF chemotherapy in premenopausal women with pathological stage II breast carcinoma: The Scottish trial. Lancet 1993;341:1293-1298.

22. Plsek P. Institute of Medicine. Crossing the Quality Chasm: A New Health System for the 21 st Century. Washington, DC National Academies Pr. 2001.

23. Love RR, Duc NB, Havighurst TC, Mohsin SK, Zhang Q, et al. Her-2/neu overexpression and response to oophorectomy plus tamoxifen adjuvant therapy in estrogen receptor-positive premenopausal women with operable breast cancer. Journal of Clinical Oncology. 2003; 21(3):453-7.

24. McGale P, Taylor C, Correa C, Cutter D, Duane $\mathrm{F}$, et al. Effect of radiotherapy after mastectomy and axillary surgery on 10-year recurrence and 20-year breast cancer mortality: meta-analysis of individual patient data for 8135 women in 22 randomised trials. Lancet (London, England). 2014;383(9935).

25. Gray RG, Rea D, Handley K, Bowden SJ, Perry P, et al. aTTom: Long-term effects of continuing adjuvant tamoxifen to 10 years versus stopping at 5 years in 6,953 women with early breast cancer. American Society of Clinical Oncology; 2013.

26. Davies C, Pan H, Godwin J, Gray R, Arriagada R, et al. Long-term effects of continuing adjuvant tamoxifen to 10 years versus stopping at 5 years after diagnosis of oestrogen receptor-positive breast cancer: ATLAS, a randomised trial. Lancet. 2013;381(9869):805-16.

27. Love RR, Duc NB, Binh NC, Van Dinh N, Havighurst TC. Symptoms associated with oophorectomy and tamoxifen treatment for breast cancer in premenopausal Vietnamese women. Breast Cancer Research and Treatment. 1999;58(3):279-84.

28. Love RR, Young GS, Laudico AV, Van Dinh N, Uy GB, et al. Bone mineral density following surgical oophorectomy and tamoxifen adjuvant therapy for breast cancer. Cancer. 2013;119(21): 3746-52.

29.Rosell J. Long-term effects of adjuvant tamoxifen treatment on cardiovascular disease and cancer: Linköping University Electronic Press; 2014.
30. Khosrow-Khavar F, Filion K, Al-Qurashi S, Torabi N, Bouganim N, et al. Cardiotoxicity of aromatase inhibitors and tamoxifen in postmenopausal women with breast cancer: a systematic review and meta-analysis of randomized controlled trials. Annals of Oncology. 2017;28(3):487-96.

31. Matthews A, Stanway S, Farmer RE, Strongman $\mathrm{H}$, Thomas $\mathrm{S}$, et al. Long term adjuvant endocrine therapy and risk of cardiovascular disease in female breast cancer survivors: systematic review. BMJ. 2018;363:k3845.

32. Wolmark N, Dunn BK. The Role of Tamoxifen in Breast Cancer Prevention: Issues Sparked by the NSABP Breast Cancer Prevention Trial (P-1). Annals of the New York Academy of Sciences. 2001;949(1):99-108.

33. Chen S, Liu H, Li J, Yang G. Risk of Gastric and Colorectal Cancer After Tamoxifen Use for Breast Cancer. Journal of Clinical Gastroenterology. 2015;49(8):666-74.

34. Kwon JS, Pansegrau G, Nourmoussavi M, Hammond GL, Carey MS. Costs and benefits of extended endocrine strategies for premenopausal breast cancer. Journal of the National Comprehensive Cancer Network. 2017;15(8):1015-21.

35. Vogel VG. The NSABP study of tamoxifen and raloxifene (STAR) trial. Expert Review of Anticancer Therapy. 2009;9(1):51-60.

36. Pisani P, Parkin D, Ngelangel C, Esteban D, Gibson L, et al. Outcome of screening by clinical examination of the breast in a trial in the Philippines. International Journal of Cancer. 2006;118(1):149-54.

37. Schnipper LE, Davidson NE, Wollins DS, Tyne C, Blayney DW, et al. American Society of Clinical Oncology statement: a conceptual framework to assess the value of cancer treatment options. Journal of Clinical Oncology. 2015;33(23):2563.

38. Joffe S, Miller FG. Ethics of cancer clinical trials in low-resource settings. Journal of Clinical Oncology. 2014;32(28):3192. 